\title{
O processo de desligamento de adolescentes em acolhimento institucional
}

\author{
Edinete Maria Rosa \\ Célia Regina Rangel Nascimento \\ Jallana Rios Matos \\ Jamile Rajab dos Santos \\ Universidade Federal do Espírito Santo
}

\begin{abstract}
Resumo
Este trabalho objetivou acompanhar o desenvolvimento de oito adolescentes, quatro meninas e quatro meninos, acolhidos em duas instituições e seus processos de desligamento institucional. Realizou-se um estudo longitudinal com base no procedimento de inserção ecológica, utilizando-se na coleta de dados diários de campo, conversas informais e roteiros de entrevistas semi-estruturadas. Os resultados foram organizados em categorias temáticas e analisados com base na Teoria Bioecológica do Desenvolvimento Humano. Apesar de a maioria dos adolescentes ter relatado manter vínculo e sentimentos positivos para com pelo menos um membro familiar e dos esforços das equipes técnicas das instituições, verificou-se dificuldade na efetivação da reinserção familiar. Conclui-se que, além da dificuldade de maior vinculação entre a instituição e alguns jovens, demonstrada pela evasão de quatro participantes, outro empecilho à reinserção é a dificuldade das famílias na superação das suas carências materiais e dos conflitos nas relações.
\end{abstract}

Palavras-chave: acolhimento institucional; desligamento institucional; adolescentes.

\begin{abstract}
The process of family reintegration: reports of adolescents in residential care. This study aimed to observe the development of eight adolescents, four girls and four boys, in two host institutions and their process of getting out of the institution. We conducted a longitudinal study based on the methodological procedure of ecological engagement, using notes concerning the observations, informal conversations and interviews. The results were organized into thematic categories and analyzed based on the Bioecological Human Development theory. Although most adolescents have reported positive feelings and preserved contact with at least one family member, family reintegration was difficult even with the efforts of the institution's technical staff. It is concluded that, besides the difficulty of closer relations between caregivers and some of the youngsters, demonstrated by the escape of four participants, another obstacle is the difficulty of families in overcoming their material needs and relationship conflicts.
\end{abstract}

Keywords: residential care; getting out; adolescents.

$\mathrm{N}$

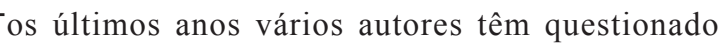
a compreensão de adolescência ainda pautada na caracterização feita por Stanley Hall, como sendo um período do desenvolvimento tipicamente problemático, tempestuoso e instável (Menandro, Trindade, \& Almeida, 2003). Exemplo deste questionamento é feito por Steinberg e Morris (2001) ao analisarem a literatura sobre adolescência nos periódicos de Psicologia nas décadas de 80 e 90, em que prevaleciam questões referentes a problemas de comportamento, ainda que houvesse evidências de que os adolescentes pesquisados vivenciavam outras realidades mais otimizadoras e promissoras. Conforme os autores, entre as pesquisas analisadas, algumas mostravam que problemas persistentes vivenciados pelos adolescentes eram, muitas vezes, anteriores à adolescência, não podendo ser associados diretamente com esse momento do desenvolvimento. Outras investigações revelavam que a maior parte dos adolescentes podia se comportar ocasionalmente de forma arriscada (como experimentar drogas lícitas e ilícitas e se comportar fora da lei), sem que isso resultasse em problemas duradouros.

Verifica-se, assim, uma mudança nos estudos da adolescência que passaram a analisar a diversidade de experiências que o adolescente pode ter, considerando sua inserção social, cultural, familiar, entre outras. Dessa forma, a adolescência deve ser concebida tendo em vista uma perspectiva contextual e de continuidade do curso da vida (Soares, 2000), ou 
seja, é importante levar em conta todo o seu processo de desenvolvimento, considerando as experiências da infância e as expectativas para o futuro.

A partir desta compreensão, o presente estudo orientase pela perspectiva contextualista da Teoria Bioecológica do desenvolvimento humano. Para Bronfenbrenner (1994) o desenvolvimento humano caracteriza-se pela continuidade e pela mudança nas características biopsicológicas do ser humano, considerando tanto a vida dos indivíduos como dos grupos através das gerações, tendo em conta as relações estabelecidas com os contextos nos quais o desenvolvimento ocorre. Para esse autor, multifatores que se interrelacionam devem ser considerados no estudo do fenômeno do desenvolvimento humano, constituindo os quatro elementos do seu modelo bioecológico (PPCT).

O primeiro elemento denomina-se de pessoa $(P)$ e envolve a análise das características biopsicológicas do indivíduo que participam tanto do direcionamento do seu desenvolvimento quanto de seus resultados. Essas características são influenciadas e atualizadas na medida em que o indivíduo interage com o seu ambiente imediato e com as pessoas caracterizando os processos proximais (Bronfenbrenner, 1994); os processos proximais $(P)$ são estabelecidos por uma relação recíproca entre a pessoa em desenvolvimento e outras pessoas de seu convívio, além de objetos e símbolos presentes nos ambientes no qual a pessoa está inserida, e para serem efetivos devem ser caracterizados por períodos duradouros e por relações progressivamente mais complexas, resultando em fundamental desenvolvimento para o sujeito (Bronfenbrenner \& Morris, 1998). O terceiro elemento são denominados contextos ecológicos (C), que compõe-se em quatro níveis desde os mais próximos e que envolvem diretamente a pessoa em desenvolvimento (microssistema e mesossistema), até os contextos que exercem influência indireta por afetarem outras pessoas com os quais o indivíduo interage (exossistema) e os contextos mais distantes (macrossistemas) compostos pelos sistemas cultural, de crenças, regras e valores que perpassam os outros contextos. Os contextos são definidos por Bronfenbrenner e Morris (1998) como os espaços nos quais as pessoas vivem e estabelecem suas relações. Finalmente, o quarto e último elemento a ser considerado como fator importante no estudo do desenvolvimento é o tempo $(T)$, pois as mudanças e continuidades se operam em função do período do ciclo vital do sujeito e do tempo histórico que ele e seu grupo vivenciam (Bronfenbrenner \& Morris, 1998).

Fundamentando-se nessa teoria, entende-se o movimento de uma instituição para outros ambientes e vice-versa como transição ecológica (Bronfenbrenner, 1979/1996). Ocorre uma transição ecológica sempre que a posição da pessoa no meio ambiente ecológico é alterada em função de uma mudança de papel, do ambiente, ou de ambos. Dessa forma, a própria adolescência é um momento de transição ecológica, uma vez que, além de envolver mudanças biológicas relacionadas à puberdade, compreende mudanças psicológicas e sociais que variam de acordo com perspectivas culturais e históricas (Siqueira, 2006).

Na nossa cultura a adolescência é um momento no qual se espera que o indivíduo vivencie mudanças que envolvem, por exemplo, a tomada de decisão sobre o seu futuro profissional, o desenvolvimento de aspectos importantes da identidade, a renegociação da relação com adultos cuidadores, a vinculação com grupos de iguais numa perspectiva relacional mais complexa, entre outros fatores (Simpson, 2001). No entanto, essas experiências serão diversas em função das características do indivíduo, do contexto no qual o adolescente se desenvolve e das interações que este estabelece com seus sistemas de relações. A vivência numa família que passa por dificuldades, a entrada numa instituição de acolhimento, e a possibilidade ou não da reinserção familiar são experiências que têm um impacto no desenvolvimento do adolescente.

A família é um importante microssistema no processo de desenvolvimento da criança e do adolescente, cujo papel primordial é oferecer segurança e proteção para o seu pleno desenvolvimento. $\mathrm{Na}$ impossibilidade de a família cumprir com seu papel, o Estado deve assumí-lo por meio da aplicação de medidas protetivas previstas no Estatuto da Criança e do Adolescente - ECA (1990), como, em caso de extrema necessidade e impossibilidade de permanência na família, a colocação em instituições de acolhimento. Nessa situação, estas passam a exercer esse papel fundamental de apoio ao desenvolvimento infanto-juvenil.

As instituições de acolhimento, por sua vez, terão um caráter transitório além de excepcional, como orienta o artigo 101 do ECA, (Estatuto da Criança e do Adolescente, 1990). Nesse período todas as instituições que compõem a rede de proteção à infância e adolescência devem unir esforços em busca do restabelecimento do direito à convivência familiar e comunitária dos acolhidos.

Contudo, a realidade brasileira mostra-se muito distante do previsto em lei quando se avalia o tempo de acolhimento. O Levantamento Nacional de Abrigos para Crianças e Adolescentes (Silva, 2004), por exemplo, revelou que o tempo de permanência nas instituições, de mais da metade $(52,6 \%)$ das crianças e adolescentes acolhidos, era superior a dois anos, sendo que algumas crianças chegavam a estar acolhidas há mais de seis anos. Os dados mostraram ainda que $87 \%$ das crianças e adolescentes acolhidos tinham família, sendo que $58 \%$ mantinham vínculo com seus familiares.

Esses dados revelam que ainda há ineficiência do Estado para promover a reinserção de crianças e adolescentes e são corroborados pelo estudo realizado por Brito (2010), no Espírito Santo, que revelou que, em 2009, 123 crianças e adolescentes estavam acolhidas nas seis instituições da capital, com tempo médio de acolhimento de 27,57 meses e ainda de 33,44 meses ao se somar o tempo em mais de uma instituição, extrapolando o que prevê a lei. Essa situação é preocupante uma vez que os efeitos de um período de institucionalização prolongado têm sido apontados na literatura, por interferirem na sociabilidade, no desenvolvimento e na manutenção de vínculos afetivos (Carvalho, 2002; Rizinni \& Rizzini, 2007; Zeanah, Smyke, Koga, \& Carlson, 2005).

Portanto, são necessárias medidas que revertam a situação de fragilidade dos vínculos familiares e promovam a reinserção das crianças e adolescentes acolhidos. Cavalcanti, Silva e Magalhães (2010), ao discutirem essa questão, apontam que é fundamental o levantamento de informações sobre os motivos que levaram ao acolhimento bem como a atualização dos dados sobre as 
condições dos acolhidos e da situação da família. Além disso, as autoras afirmam que é preciso que a equipe preste atenção nos sinais emitidos pelas pessoas envolvidas no processo (família, instituição, acolhidos) como a "manifestação regular e crescente de gestos, palavras e atitudes" que possam ajudar a avaliar e promover as condições favoráveis à reinserção familiar (p. 1160). Nesse sentido, é importante que a instituição desenvolva estratégias de aproximação com os pais e destes com a instituição (Cavalcanti et al., 2010).

Siqueira, Zoltowsi, Giordani, Otero e Dell'Aglio (2010) apontam que estudos sobre o tema mostram que uma série de procedimentos podem facilitar o sucesso da reinserção familiar, como a preparação prévia da família que inclui o encaminhamento de ações que podem diminuir seus fatores de risco, a visita periódica entre a família e os filhos acolhidos e a promoção de outras formas de contato para manutenção do vínculo, além da participação ativa da família e dos membros acolhidos.

A participação ativa nesse processo envolve, entre outras coisas, dar voz às crianças e aos adolescentes em situação de acolhimento, e para isso é preciso promover momentos de conversa e valorizar o que eles têm a dizer (Rossetti-Ferreira, Sólon, \& Almeida, 2010). Para Rossetti-Ferreira et al. (2010, p. $71)$ “(...) por meio da conversa, as crianças e os adolescentes podem aprender sobre si e construir suas histórias, uma vez que as experiências narradas ao outro favorecem a construção de seus próprios significados sobre o mundo e sobre si”. Essa posição é reforçada por outros autores que estudam a adolescência e consideram que, para poder oferecer espaços adequados à realidade dos jovens, é preciso promover diálogos que façam surgir suas necessidades, além de apoiar e contribuir para que estes entendam e assimilem suas próprias mudanças (Oliveira \& Egry, 1997; Ozella, 2003).

A partir dessas considerações, este estudo teve como proposta acompanhar o desenvolvimento de adolescentes em processo de desligamento institucional após um período de acolhimento em instituições de um município do Estado do Espírito Santo. Mais especificamente buscou investigar, a partir da percepção de adolescentes acolhidos de ambos os sexos, como ocorreu a entrada na instituição e o tempo de permanência na mesma, a avaliação que os mesmos fazem da instituição enquanto um lugar de proteção ou não e dos vínculos estabelecidos nesse ambiente, e ainda como se dá a preparação para o desligamento, a partir do restabelecimento das relações dos adolescentes com a rede de apoio social e afetivo no contexto familiar.

\section{Metodologia}

\section{Participantes}

Participaram da pesquisa oito adolescentes, quatro meninas e quatro meninos entre 14 e 18 anos residentes em duas instituições de acolhimento de um município do Estado do Espírito Santo, uma que acolhe adolescentes do sexo feminino e outra que acolhe adolescentes do sexo masculino. Os participantes serão apresentados por nomes fictícios, mantendo assim o sigilo de suas identidades. Foram convidados a participar da pesquisa todos os adolescentes que estavam residindo nas instituições no momento da pesquisa e que foram indicados pela equipe técnica como já tendo iniciado o processo de desligamento institucional; somente um não aceitou o convite.

\section{Instrumentos e procedimentos}

A coleta dos dados foi realizada por meio de entrevistas individuais com roteiro semi-estruturado que buscou levantar informações sobre a caracterização dos participantes; a avaliação dos processos de institucionalização e desinstitucionalização, abordando a convivência na instituição e a manutenção dos vínculos familiares.

Um diário de campo também foi utilizado para registro das observações e informações obtidas durante o processo de inserção ecológica, que consistiu do acompanhamento da dinâmica de funcionamento da instituição, por meio de visitas, observações, conversas informais e realização das entrevistas. A inserção ecológica proposta por Cecconello e Koller (2003) consiste na operacionalização da Teoria Bioecológica do desenvolvimento humano atentando-se para quatro elementos do modelo PPCT. O método "tem como objetivo avaliar os processos de interação das pessoas com o contexto no qual estão se desenvolvendo" (Prati et al., 2008, p. 161). Embora Bronfenbrenner e Morris (1998) tenham frisado a importância da investigação conjunta dos quatro elementos que compõem a Teoria Bioecológica, nós focamos nossa análise nos contextos familiar e institucional e nos processos proximais estabelecidos com membros da instituição e da família.

Os participantes e as instituições responsáveis pelos mesmos foram informados sobre os objetivos da pesquisa e sobre os procedimentos éticos por meio da leitura de um termo de consentimento livre e esclarecido, e após suas concordâncias foram solicitadas as assinaturas dos mesmos. A pesquisa teve aprovação do Comitê de Ética em Pesquisa da Universidade Federal do Espírito Santo sob número 059/09.

De junho a agosto de 2009, conversas informais com a equipe técnica permitiram identificar os adolescentes que poderiam participar da pesquisa, ou seja, aqueles que já estavam em processo de desligamento institucional. As primeiras visitas ocorreram no período de agosto de 2009 a março de 2010, tanto nas instituições quanto nos espaços em que os adolescentes frequentavam nas suas rotinas diárias, como áreas de lazer locais. Posteriormente realizamos as primeiras entrevistas com os oito adolescentes do sexo feminino e masculino, constituindo a primeira parte da investigação. Entre julho e agosto de 2010 novos contatos foram realizados com as instituições e constatouse que somente um dos rapazes havia saído da instituição devido à maioridade. Por intermédio do Programa de Proteção à Criança e ao Adolescente Ameaçados de Morte conseguimos nos encontrar com o adolescente e realizar uma entrevista nas dependências da universidade. Durante a segunda parte da investigação, três dos meninos que participaram das primeiras entrevistas evadiram, tendo a instituição perdido contato com eles. Em relação às adolescentes, uma evadiu-se e três estavam ainda em processo de reinserção familiar. Elas continuaram a ser acompanhadas na instituição de acolhimento e foram realizadas outras entrevistas no início de 2011, após período de férias com 
as famílias.

\section{Resultados}

Participaram da primeira etapa de entrevistas oito adolescentes, quatro meninos (Ross, Chandler, Joey e David) e quatro meninas (Ágata, Pérola, Esmeralda, Jade), entre elas duas irmãs. Na segunda etapa de entrevistas participaram apenas quatro adolescentes: Ross, Pérola, Ágata e Jade, os outros adolescentes evadiram da instituição.

\section{As adolescentes}

Ágata e Pérola (irmãs - 16 e 15 anos). Ágata estava acolhida há cinco anos e sua irmã Pérola há quatro anos na instituição na qual a pesquisa foi realizada, contudo, se contarmos o tempo total de acolhimento considerando outras instituições nas quais as irmãs passaram, somam-se 14 anos de acolhimento institucional. O motivo relatado para serem afastadas da família foi que a sua mãe não tinha condições de criá-las devido ao grande número de irmãos que elas possuíam (sete irmãos). Relataram manter vínculo afetivo com sua mãe, visitando-a nos finais de semana e também com uma irmã mais velha.

Esmeralda (15 anos). Estava acolhida na instituição na qual foi entrevistada há quatro meses, porém, com o tempo em que esteve acolhida em outras instituições somava-se um total de seis anos de acolhimento. O último acolhimento se deu devido a uma briga com a mãe que acabou por expulsá-la de casa juntamente com um irmão. Falou que antes desta briga ela havia "entrado na vida do crime", traficando e usando drogas, o que pode ter desencadeado a briga com a mãe.

Jade (16 anos). É a que estava há menos tempo acolhida, sendo cinco meses o período em que se encontrava na instituição, não tendo histórico de outros acolhimentos. O motivo deste foi ter sofrido maus-tratos pelo seu companheiro e pai de sua filha. No momento do acolhimento ela estava grávida de sete meses e veio a ter a criança na instituição. A adolescente revelou manter contato com seu pai e seu irmão, que a visitavam na instituição.

\section{O microssistema institucional das meninas}

$\mathrm{Na}$ instituição de acolhimento das adolescentes a rotina proposta incluía a participação das mesmas nas atividades de limpeza e organização do espaço. Elas eram incentivadas a participar também de atividades esportivas, cursos profissionalizantes, escola, além de serem observadas questões referentes à saúde como consultas a médicos e boa alimentação. Elas recebiam visitas de familiares, nas quintas-feiras e aos sábados, aquelas que desejassem poderiam fazer visitas aos familiares.

A sede da instituição era uma casa de dois pavimentos, bem conservada e com vários móveis. Eram disponibilizados para as adolescentes: computadores e acesso à internet; linha telefônica; materiais escolares e didáticos necessários à vida escolar; bem como vestuários e alimentação. O quintal da residência constituía um espaço agradável para a convivência das adolescentes e nele havia uma árvore frutífera e um balanço.

Quanto à segurança dentro da instituição, três adolescentes responderam que a instituição de acolhimento era um lugar de segurança para elas. Ao serem questionadas sobre o que transmitia segurança na instituição, elas mencionaram as educadoras: "As educadoras, porque elas mesmas que atendem a porta quando tem alguém esquisito" (Pérola).

Somente Esmeralda disse que não sentia segurança na instituição, afirmando que a única pessoa que lhe transmitia segurança era a sua mãe. Justificou que na instituição se sentia temerosa quanto aos acontecimentos na família: "Eu tenho medo de estar aqui dentro e eu sei que tá (sic) acontecendo um monte de coisa ruim com minha família, e eu tenho medo de acontecer algo pior, além do que tá (sic) acontecendo".

Verificou-se que todas as adolescentes passaram por diversas transições ecológicas, atestadas pelos registros em suas fichas de acompanhamento existentes nas instituições, sendo estas caracterizadas pela entrada e pelas mudanças de instituições ao longo de vários anos, e pelos momentos prolongados de convivência com a família em períodos de férias, no caso de Jade, Ágata e Pérola. Destaca-se, ainda, que duas adolescentes já eram mães, portanto, tendo passado por uma mudança de papéis, o que caracteriza também uma transição ecológica.

\section{Os processos proximais na instituição sob a perspec- tiva das adolescentes}

Todas as adolescentes relataram que foram bem recebidas na instituição, tanto pela equipe técnica quanto pelos educadores e demais adolescentes acolhidas, com algumas exceções. Todas avaliaram as relações como positivas apesar de terem alguns desentendimentos e atritos devido às "fofocas" e às críticas, geradoras de baixa confiança entre algumas das adolescentes. As duas participantes que são irmãs ressaltaram a boa relação que uma tem com a outra, pautada principalmente na confiança e apoio afetivo mútuo. Entre as meninas, foram destacados os bons vínculos com a coordenadora do abrigo, bem como com a assistente social, a psicóloga e os educadores que se singularizavam pelos processos de identificação, confiança e diálogos.

\section{A manutenção dos vínculos familiares necessários ao processo de desligamento}

Ágata e Pérola passavam os finais de semana com a mãe e avaliaram positivamente o contato com ela. Relataram uma irmã e um irmão como membros da família, sendo o último avaliado por uma delas como muito ciumento. Para elas a família constitui um microssistema importante e presente, com pessoas significativas que fazem parte de suas vidas, consideradas uma fonte de apoio social e afetivo. Com o objetivo de promover o estreitamento e resgate dos laços familiares, a equipe técnica da instituição conseguiu viabilizar que as duas irmãs passassem o período de férias escolares em casa, durante aproximadamente 30 dias nos meses de dezembro e janeiro de 2010. Após esse período, as adolescentes e a mãe delas foram entrevistadas para avaliar como elas perceberam essa convivência familiar.

Ágata e Pérola avaliaram a convivência familiar durante as férias como sendo positiva. Relatam que se divertiram, passearam, visitaram parentes, fizeram amizades e auxiliaram nas tarefas domésticas. As duas adolescentes apontaram como aspecto negativo a presença do irmão mais velho, com quem tem 
uma relação mais conflituosa e menos proximidade. Segundo Ágata, o irmão as criticava e as castigava. Como descrito a seguir:

Aí, ele queria bater na minha irmã, eu peguei e falei com minha mãe isso, cheguei pra K. e falei né que ele estava fazendo muita maldade comigo e com Pérola, a gente não gosta disso, a gente não foi pra lá para ser espancada de ninguém, a gente foi pra lá pra se divertir, conhecer mais um pouco a nossa família (Ágata).

Ágata apontou que tinha um relacionamento mais próximo com a irmã mais velha, pessoa com quem mais conversou quando esteve com a família e com quem podia contar quando alguma coisa acontecia com ela e a irmã. Pérola relatou que conversou tanto com a mãe quanto com a irmã; com esta última ela disse ter conversado sobre namorados, estudos, entre outras coisas. Para as duas meninas a recepção familiar foi considerada boa. No entanto, Pérola acrescentou que esperava que as situações que ela vivenciou com o irmão não voltassem a acontecer nas próximas visitas. Ela relatou que a equipe da instituição de acolhimento e do Centro de Referência da Assistência Social CRAS iriam intervir no comportamento do irmão para prevenir possíveis agressões e viabilizar a reinserção familiar. Em relação à verificação de mudanças no relacionamento familiar nesse período que estiveram afastadas, Ágata relatou que aconteceram pelo fato de a irmã ter voltado a morar com a família e esta ajudava à mãe a por limites com os irmãos.

Foi feita também uma entrevista com a mãe das meninas investigando suas percepções sobre o período de convivência durante as férias. A mãe, em poucas palavras, relatou que desde quando as filhas saíram de casa para a instituição de acolhimento, ela recebe apoio do Centro de Referência Especializado de Assistência Social-CREAS e do CRAS, além de cestas básicas de irmãs de caridade da igreja católica. Sobre o período que as filhas passaram em casa, ela relatou que gostou bastante pelo fato da oportunidade que as filhas tiveram de conhecerem melhor os irmãos e vice-versa. Ela contou que os irmãos também ficaram felizes com a presença delas nesse período. Contudo, a mãe contou que o mais difícil foi que Ágata e Pérola quase não ficaram em casa, pois passearam muito na casa das amigas.

Jade citou como membros de sua família o pai, o irmão, a avó, os primos e os tios, mas somente seu pai e seu irmão a visitavam na instituição e eram as pessoas consideradas mais importantes para ela. Jade manifestou afeto pelo pai e interesse em retornar ao convívio da família:

Gostaria de morar com minha família, porque ele (o pai) vai assim, ele vai me compreender bastante, ou assim, me dá as coisas que eu preciso, vai é... me ajudar, ajudar minha filha, entendeu? Vai assim educar muito bem como ele sempre fez.

Durante o período de natal e ano-novo Jade e sua filha passaram uma semana na casa de seu pai. Ela contou que foi bem recebida e avaliou a convivência nesse período como boa. Contou que se divertiu, visitou parentes e auxiliou o pai nas tarefas domésticas, o que considerou prazeroso pela oportunidade que teve de cuidar da casa e da filha. A pessoa com quem mais conversou nesse período foi com sua tia, de quem recebeu alguns conselhos, e sentiu o interesse em saber de sua história e os motivos de ter ficado na instituição. Essa tia também a ajudava nos cuidados com a filha.

Jade apontou ainda que não gostou de alguns comportamentos de seu pai, como, por exemplo, os momentos em que estava alterado pela ingestão de bebidas alcoólicas e era agressivo com o seu irmão. Porém, disse que isso não acontecia com ela porque não era "quieta" como o irmão, não deixando o pai agir da mesma forma com ela. Jade relatou também que não gostou de ter passeado pouco tempo, e que queria ter ficado menos em casa e saído mais. Em relação à verificação de mudanças que ocorreram neste período em que esteve afastada, Jade considerou que seu pai passou a ser mais atencioso.

Esmeralda citou como membros de sua família: sua mãe, seu padrasto, sua irmã e seus irmãos, mas não manifestou interesse em retornar para o convívio de nenhum deles, nem se esforçava em manter vínculos. Já os relatos de Jade, Ágata e Pérola indicavam que elas mantinham relações próximas com seus familiares, por meio de visitas recebidas na instituição e por contato via telefone.

\section{Informações das adolescentes sobre o processo de desligamento institucional}

A primeira pergunta diretamente relacionada ao processo de desligamento institucional e possível reinserção familiar foi se eles recebiam informações sobre o processo judicial deles e quem dava as informações. Todas as meninas responderam que recebiam informações sobre seus processos e a pessoa que passava as informações era a psicóloga. A principal informação que as adolescentes disseram recordar dizia respeito ao prazo para irem embora para casa. Dessa forma, percebe-se a expectativa que elas tinham de retornarem para seus lares e para o convívio com alguém da família. Elas também foram unânimes em considerar que a equipe técnica se esforçava para promover a reinserção. Os meios para isso eram cobrando do Juiz e conversando com os familiares.

\section{Os adolescentes}

Ross (18 anos). Passou a viver sozinho com apenas 10 anos depois de sofrer maus-tratos por parte da avó com quem viveu dos sete aos 10 anos. Quando ele era ainda muito pequeno sua mãe morreu e ele viveu com seus bisavós até os sete anos, quando também estes faleceram. Depois que fugiu da casa da avó, Ross viveu pelas ruas tendo passado por algumas instituições de acolhimento, mas em nenhuma ficou por longo tempo sempre retornando para as ruas. Envolveu-se com o tráfico de drogas até que, com quase 17 anos, sofreu um atentado e foi internado em um hospital, de onde retornou para a instituição, na condição de paraplegia, porque não tinha nenhum parente que o acolhesse. Devido ao atentado foi inserido no Programa de Proteção a Crianças e Adolescentes Ameaçados de Morte (PPCAAM).

Chandler (15 anos). Permaneceu institucionalizado por três anos. Foi acolhido na instituição devido a sua situação de rua, provavelmente provocada por negligência familiar. O adolescente tinha uma irmã também institucionalizada que o visitava semanalmente na instituição. Entretanto, apresentava pouco vínculo com sua família de origem.

Joey (14 anos). Permaneceu institucionalizado por três meses. Foi acolhido na instituição devido à situação de rua e 
o envolvimento com tráfico de drogas. O adolescente possuía vínculos afetivos com sua família de origem, em especial sua mãe que o visitava constantemente.

David (15 anos). Foi acolhido pela primeira vez e estava na instituição há quatro meses. O motivo do acolhimento, segundo o adolescente, foi devido ao fato de seu padrasto ter molestado sua irmã que hoje está acolhida em outra instituição. Com isso, o padrasto foi preso e sua mãe não teve condições de cuidar dele e da irmã.

\section{O microssistema institucional dos meninos}

A instituição de acolhimento dos meninos era uma casa ampla com boas instalações físicas e em bom estado de conservação. A casa tinha um quintal grande todo gramado onde aconteciam as festas comemorativas reunindo todas as outras casas de acolhimento. A rotina diária dos adolescentes era caracterizada por atividades diversificadas envolvendo esportes, educação, cultura e lazer. Nos finais de semana a instituição permitia que eles recebessem visitas das famílias e pessoas da comunidade. Também poderiam realizar visita aos familiares e amigos. A eles eram disponibilizados computadores e acesso à internet, linha telefônica, materiais escolares e didáticos, vestuários e alimentação. Os adolescentes também participavam das atividades de limpeza e da organização do espaço onde estavam acolhidos.

Quanto à segurança dentro da instituição, todos os adolescentes entrevistados responderam que a instituição de acolhimento era um lugar de segurança para eles, e ao serem questionados sobre o que transmitia segurança na instituição, os meninos responderam: "Ah, o convívio, né?" (Ross). "Os amigos" (Joey). "A casa, um monte de coisas" (David).

Todos os adolescentes passaram por transições ecológicas (família x instituição), mas somente Ross passou por mais de uma instituição de acolhimento. Ross também foi o que vivenciou o maior número de rompimento dos vínculos familiares, tendo morado com a mãe, a tia, os bisavós e uma avó. Além disso, vivenciou a morte de sua mãe e de seus bisavós que, segundo ele, eram pessoas significativas em sua vida. Todos relataram as transições ecológicas destacando alguma perda afetiva, contudo, para todos, as novas situações de vida eram oportunidades de novos relacionamento e crescimento humano.

\section{Os processos proximais na instituição sob a perspec- tiva dos adolescentes}

Entre os adolescentes, três deles relataram terem sido bem recebidos na instituição, tanto pela equipe técnica quanto pelos educadores e demais adolescentes acolhidos. Apenas Ross comentou que não foi bem recebido pelos outros adolescentes devido à deficiência física, tendo caracterizado o tratamento diferenciado recebido como preconceituoso. Os meninos apresentaram uma maior identificação e vínculo uns com os outros que as meninas. Alguns já se conheciam de outros espaços, e o tempo de acolhimento juntos pode ser uma explicação para este fato. No entanto, havia em alguns momentos, brigas e desavenças entre os adolescentes, consequências do convívio diário e das implicações decorrentes disso.

A equipe técnica e os educadores foram considerados como fonte de apoio social e afetivo. Os meninos consideraram que eram pessoas com quem eles podiam contar para conversar, desabafar e pedir conselhos.

\section{A manutenção dos vínculos familiares necessários ao processo de desligamento}

Em relação à convivência familiar, não foi possível obter informações da convivência de David, pois o adolescente evadiuse da instituição antes que essa questão tivesse sido investigada. Em momento posterior foi possível saber que ele voltou para casa por conta própria.

Chandler apresentou poucos vínculos com sua família de origem, afirmou não poder visitá-los e que apenas recebia visita dos avós no dia de seu aniversário. Porém, verbalizou que mantinha contato com sua irmã, acolhida em outra instituição, e dizia ter um bom relacionamento com ela. Mencionou a mãe como a pessoa com quem gostaria de morar quando saísse da instituição. Não foi possível obter mais informações sobre o fortalecimento do vínculo com sua família e sua reinserção, pois o jovem evadiu-se e a instituição perdeu contato com ele.

Joey mostrou ter vínculos afetivos com sua família de origem, em especial sua mãe que sempre o visitava. O adolescente citou a mãe como pessoa com quem gostaria de morar após sair da instituição. Também não foi possível acompanhar o percurso de reinserção de Joey, pois este evadiu-se e por isso foi perdido o contato com o mesmo.

Ross afirmou também não manter mais contato com seus familiares, já que a mãe e os bisavós, com quem tinha bom relacionamento, já tinham falecido. Contou ainda que seu único contato familiar era uma irmã adotiva, com quem falava, na maioria das vezes, por telefone.

\section{Informações dos adolescentes sobre o processo de desligamento institucional}

Somente David afirmou que recebia notícias sobre seu processo judicial, dois adolescentes afirmaram que só recebiam notícias quando tinham audiência e todos afirmaram que as notícias eram dadas pelo psicólogo. Ross declarou que passou a receber notícias com mais frequência depois que foi inserido no PPCAAM. Dois adolescentes acusaram a morosidade da justiça como justificativa para a demora no processo de desligamento institucional. Ross disse que tentou por conta própria uma reaproximação com sua avó, mas logo se desentenderam. Afirmou que se o processo tivesse ocorrido com maior rapidez, ele poderia ter sido adotado por uma família.

Apesar de uma avaliação não muito positiva dos meninos quanto ao acesso às informações, três deles afirmaram que a equipe se esforçava para promover a reinserção: "Quando eu tô ( $\mathrm{sic}$ ) com raiva eles falam: Pense que está na hora de você sair... eles ajudam. Acho que sim" (David). "Sim, eles tentam falar com a família e com o juizado" (Chandler). "De vez em quando eles ligam pra minha família, falam pra me visitar, eles vem de vez em quando" (Joey).

\section{Concretização do processo de desligamento institu- cional}

Por ter atingido a maioridade, Ross foi o único adolescente 
que teve o desligamento legal da instituição durante o período de 18 meses de acompanhamento dos adolescentes. O jovem passou a dividir um apartamento com um amigo também protegido pelo PPCAAM. Para ele, a participação da instituição de acolhimento no processo de desligamento não foi tão significativa, tendo recebido mais apoio por parte do Programa PPCAAM: "No abrigo, assim, não foi essas coisas todas. O Programa me auxiliava mais para quando eu saísse dali". Como ajuda recebida do programa Ross apontou: "Financeiramente, eles me ensinaram a guardar dinheiro. Como seria gasto o dinheiro. Quanto precisava para montar minha casa, segurar a meta. Me deram (sic) a maior. Me fizeram planejar como seria o mês seguinte. Onde seria (sic) comprada (sic) as coisas e isso foi essencial".

Já fora da instituição de acolhimento frequentava a escola, e nos finais de semana saía para passear com os colegas. Sobre as relações familiares afirmou que continuou mantendo contato com sua irmã por telefone. A respeito de suas relações com a instituição de acolhimento após a sua saída da mesma, o adolescente expôs que mantinha as amizades feitas lá, porém, não frequentava mais o espaço, porque não havia na equipe técnica alguém significativo para ele. Fazendo nova avaliação sobre a sensação de segurança, o adolescente considerou que tanto na instituição de acolhimento quanto em sua nova moradia não se sentia seguro. $\mathrm{Na}$ instituição ele afirmou sentir-se muito vulnerável, já em sua moradia atual ele relatou sentir "medo normal" do dia a dia, porque, segundo ele, sempre se está correndo riscos. Em relação à ameaça de morte que recebia por conta do tráfico de drogas, Ross apontou que, com a participação no PPCAAM, sentia-se mais protegido. "Se eles [PPCAAM] descobrirem que você está sendo perseguido, eles vão até você, eles te tiram de lá. E vão te levar para um lugar mais seguro. Eles ajudam a você a voltar à sociedade. Eles atuam em vários temas que ajudam bastante" (Ross).

\section{Discussão}

Entre os motivos para o acolhimento dos adolescentes de ambos os sexos verificou-se: negligência, maus tratos, abandono, envolvimento com o tráfico, situação de rua e pobreza, ainda que, conforme o ECA, este último não seja considerado motivo para afastamento do convívio familiar e, consequente, acolhimento institucional. Este quadro está relacionado à realidade de muitos jovens brasileiros se considerarmos que, de acordo com o IPEA (De Vizia, 2010), 30\% dos jovens do país vivem em famílias com renda familiar per capita abaixo de meio salário mínimo por mês, e apenas $15 \%$ são oriundos de famílias com renda familiar per capita superior a dois salários mínimos, ou seja, a situação de pobreza atinge boa parte dos nossos jovens.

$\mathrm{Na}$ avaliação tanto dos meninos quanto das meninas, a instituição de acolhimento cumpre com sua função, prevista no ECA, ao oferecer boas instalações físicas; suporte afetivo; acesso à educação, à saúde e ao lazer; além de promover e acompanhar ações cujo objetivo é manter e estreitar o convívio familiar. Para a maioria deles o local oferece segurança e os vínculos estabelecidos com os técnicos e educadores são citados como fontes de segurança.

Bronfenbrenner (2001) enfatizou que, além das características físicas dos ambientes, o envolvimento afetivo que pode haver entre as pessoas são fortes determinantes para o estabelecimento de processos proximais. Nesse sentido, toda a equipe das instituições, constituída pelos técnicos e educadores, foi avaliada pelos adolescentes como fonte de relações seguras. Além disso, observou-se que na instituição de acolhimento das meninas houve iniciativas mais pontuais para a promoção do estreitamento dos vínculos afetivos com os familiares, como os períodos de férias que as adolescentes passaram com suas famílias, convívio que favorece o trabalho em direção à reinserção familiar.

Embora a avaliação geral que os adolescentes fizeram das instituições tenha sido positiva, isso não foi o suficiente para que parte deles permanecesse na mesma. Vale lembrar que entre os meninos, onde houve maior número de evasão, a avaliação sobre a equipe técnica quanto ao investimento no desligamento e a obtenção de informação a respeito de sua situação foi menos positiva do que entre as meninas. Um dos adolescentes se sentiu mais apoiado pelo Programa de Proteção a Crianças e Adolescentes Ameaçados de Morte do que pela instituição de acolhimento.

Poucos estudos discutem a questão da evasão nas instituições de acolhimento; uma explicação possível para a evasão é a dada por Silva (2010), a busca por uma situação de liberdade e autonomia em contraposição à rotina e às regras da instituição, principalmente considerando adolescentes que já estiveram nas ruas. Dois dos meninos que evadiram-se, Chandler e Joye, estavam morando nas ruas antes do acolhimento, um deles estava também envolvido com o tráfico de drogas. Esmeralda também tinha envolvimento com o tráfico antes do acolhimento e havia sido expulsa de casa. Outra motivação, segundo a autora, é a busca dos vínculos e o retorno aos ambientes anteriores ao acolhimento; no caso de David, o adolescente voltou sozinho para a casa da família.

No relato dos adolescentes sobre o microssistema familiar, verificou-se que a família, embora não fosse o microssistema central na vida destes adolescentes no momento do estudo, foi fortemente representada e fazia parte das expectativas para o futuro, mesmo quando marcada por histórias de maus-tratos e negligência. Chandler e Joey, embora tenham se evadido antes da reinserção ser promovida pela instituição, disseram que gostariam de morar com a mãe. Ross, que teve uma história de maus-tratos sofridos desde os sete anos de idade e mesmo tendo perdido as pessoas de maior importância em sua vida (mãe e avós) tentou uma reaproximação com outros parentes. As adolescentes Ágata, Pérola e Jade, que apresentaram maior possibilidade de reinserção familiar, tinham muitas expectativas com relação à sua volta para casa e ao convívio com suas famílias de origem. No entanto, durante o estudo, o único processo de desligamento concretizado foi o de Ross.

Cavalcante, Silva e Magalhães (2010) analisam que nem sempre as condições familiares que levaram crianças e adolescentes a serem institucionalmente acolhidos são realmente superadas durante o período de acolhimento, o que dificulta a reinserção. Problemas financeiros, materiais e conflitos emocionais podem ser amenizados, mas permanecem frequentes no cotidiano das famílias. Este aspecto foi observado 
neste estudo, pois durante o período em que estiveram com as famílias nas férias alguns dos conflitos que dificultavam as relações das adolescentes nesse contexto foram evidenciados, como as agressões do irmão de Ágata e Pérola e o alcoolismo do pai de Jade.

Verifica-se, portanto, que, para que o desligamento institucional e a reinserção familiar aconteçam, é preciso fortalecer a rede de apoio às famílias durante todo o processo. Investir em políticas e serviços que resgatem condições dignas para as famílias; repensar as situações e condições que têm levado crianças e adolescentes ao acolhimento institucional; e, sendo necessário o acolhimento, ter programas específicos e profissionais capacitados para viabilizar e acompanhar a reinserção social e familiar são algumas das ações que o governo e os programas de atendimento institucional podem fazer em curto, médio e longo prazos (Cavalcante et al., 2010; Rizini \& Rizini, 2007; Siqueira et al., 2010).

\section{Referências}

Brito, C. O. (2010). O processo de reinserção familiar de crianças e adolescentes em acolhimento institucional. (Dissertação de Mestrado). Universidade Federal do Espírito Santo, Vitória.

Bronfenbrenner, U. (1994). Ecological models of human development. In T. Husen \& T. N. Postlethwaite (Orgs.), International encyclopedia of education ( $2^{\mathrm{a}}$ ed.) (Vol. 3, pp. 1643-1647). Oxford, England: Pergamon Press/Elsevier Science.

Bronfenbrenner, U. (1996). A ecologia do desenvolvimento humano. Porto Alegre: Artes Médicas. (Obra original publicada em 1979)

Bronfenbrenner, U. (2001). The bioecological theory of human development. In N. J. Smelser \& P. B. Baltes (Orgs.), International encyclopaedia of the social and behavioural sciences (pp. 6963-6970). Oxford, UK: Elsevier.

Bronfenbrenner, U., \& Morris, P. A. (1998). The ecology of development processes. In W. Damon (Org. Série) \& R. M. Lerner (Org. Vol.), Handbook of child psychology: Theoretical models of human development (Vol. 1., pp. 993-1027). Nova Iorque: John Wiley \& Sons.

Carvalho, A. (2002) Crianças institucionalizadas e desenvolvimento: Possibilidades e desafios. In E. Lordelo, A. Carvalho \& S. H. Koller (Coord.). Infância brasileira e contextos de desenvolvimento. São Paulo: Casa do Psicólogo.

Cavalcante, L. I. C., Silva, S. S. C., \& Magalhães, C. M. C. (2010). Institucionalização e reinserção familiar de crianças e adolescentes. Revista Mal-estar e Subjetividade, X(4), 1147-1172.

Cecconello, A. M., \& Koller, S. H. (2003). Inserção ecológica na comunidade: Uma proposta metodológica para o estudo de famílias em situação de risco. Psicologia: Reflexão e Crítica, 16(3), 515-524.
De Vizea, B. (2010). Como nossos pais? Desafios do desenvolvimento. Revista mensal de informações e debates do IPEA. Recuperado de http://desafios2. ipea.gov.br/sites/000/17/edicoes/60/pdfs/rd60not02.pdf

Estatuto da Criança e do Adolescente (1990). Diário Oficial da União. Lei Federal 8.069 de 13 de julho de 1990, Brasília, DF.

Menandro, M. C. S., Trindade, Z. A., \& Almeida, A. M. O. (2003). Representações sociais da adolescência/juventude a partir de textos jornalísticos (1968-1974 e 1996-2002). Arquivos Brasileiros de Psicologia, 55(1), 45-60.

Oliveira, M. A. C., \& Egry, E. Y. (1997). A adolescência como um constructo social. Revista Brasileira Crescimento e Desenvolvimento Humano 7(2), $12-21$.

Ozella, S. (2003). Adolescência e os psicólogos: A concepção e a prática dos profissionais. In S. Ozella (Org.), Adolescências construídas: a visão da psicologia sócio-histórica (pp. 17-40). São Paulo: Cortez.

Prati, L. E., Couto, M. C. P. P., Moura, A., Poletto, M, \& Koller, S. H. (2008). Revisando a inserção ecológica: uma proposta de sistematização. Psicologia: Reflexão Crítica, 21(1), 160-169.

Rizinni, I., \& Rizinni, I. (2007). Acolhendo crianças e adolescentes-experiências de promoção do direito à convivência familiar e comunitária no Brasil ( $2^{\mathrm{a}}$ Ed.) São Paulo, SP: Cortez.

Rossetti-Ferreira, M. C., Sólon, L. A. G., \& Almeida, Y. G. (2010). A delicada arte da conversa e da escuta. In D. C. F. Bernardi (Org.), Cada caso é um caso: estudos de caso, projetos de atendimento (pp. 61-73). São Paulo, SP: Associação Fazendo História, NECA - Associação dos Pesquisadores de Núcleos de Estudos e Pesquisas sobre a Criança e o Adolescente.

Silva, E. R. A. (2004). O direito à convivência familiar e comunitária: os abrigos para crianças e adolescentes no Brasil. Brasília: IPEA/CONANDA.

Silva, M. E. S. (2010). Acolhimento institucional: a maioridade e o desligamento. (Dissertação de Mestrado). Universidade Federal do Rio Grande do Norte, Natal.

Simpson, A. R. (2001). Ser padres de adolescentes: una síntesis de la investigación y una base para la acción (Raising teens: a synthesis of research and a foundation for action). Boston: Centro para La Comunicación de Salud, Escuela de Salud Pública de Harvard. Recuperado de http://www.paho.org/ Spanish/AD/FCH/CA/serpadresadol.pdf

Siqueira, A. C. (2006). Instituições de abrigo, família e redes de apoio social e afetivo em transições ecológicas na adolescência. (Dissertação de Mestrado). Universidade Federal do Rio Grande do Sul, Porto Alegre. (000522590)

Siqueira, A. C., Zoltowsi, A. P., Giordani, J. P., Otero, T. M., \& Dell'Aglio, D. D. (2010). Processo de reinserção familiar: estudo de casos de adolescentes que viveram em instituição de abrigo. Estudos de Psicologia, 15(1), 07-15.

Soares, C. (2000). De juventudes, transiciones y el fin de las certidumbres. Papeles de Población, 6(26), 9-23.

Steinberg, L. E., \& Morris, A.S. (2001). Adolescent development. Annual Review of Psychology, 52, 83-110.

Zeanah, C. H., Smyke, A. T., Koga, S. F., \& Carlson, E. (2005). Attachment in institutionalized and community children in Romania. Child Development, $76,10-15$.

Edinete Maria Rosa, doutora em Psicologia Social pela Universidade de São Paulo (USP), é professora adjunta da Universidade Federal do Espírito Santo (UFES). Endereço para correspondência: Universidade Federal do Espírito Santo, Centro de Ciências Humanas e Naturais. Avenida Fernando Ferrari, Goiabeiras. CEP: 29075-910 - Vitória, ES. E-mail: edineter@gmail.com

Célia Regina Rangel Nascimento, doutora em Psicologia pela Universidade Federal do Espírito Santo (UFES), é professora adjunta da Universidade Federal do Espírito Santo (UFES). E-mail: celiarrn@gmail.com Jallana Rios Matos, é graduanda em Psicologia pela Universidade Federal do Espírito Santo (UFES). E-mail: jallana_rios@hotmail.com

Jamile Rajab dos Santos, é graduanda em Psicologia pela Universidade Federal do Espírito Santo (UFES). E-mail: jrajab@gmail.com 